\title{
A quick and simple FISH protocol with hybridization-sensitive fluorescent linear oligodeoxynucleotide probes
}

\author{
DAN OHTAN WANG, ${ }^{1,2,5}$ HITOMI MATSUNO ${ }^{3}$ SHUJI IKEDA, ${ }^{2}$ AKIKO NAKAMURA, ${ }^{2}$ \\ HIROYUKI YANAGISAWA, ${ }^{2}$ YASUNORI HAYASHI, ${ }^{3}$ and AKIMITSU OKAMOTO ${ }^{2,4,5}$ \\ ${ }^{1}$ Institute for Integrated Cell-Material Sciences, Kyoto University, Kyoto 606-8501, Japan \\ ${ }^{2}$ Advanced Science Institute, RIKEN, Wako City, Saitama 351-0198, Japan \\ ${ }^{3}$ Brain Science Institute, RIKEN, Wako City, Saitama 351-0198, Japan \\ ${ }^{4}$ PRESTO, Japan Science and Technology Agency, Kawaguchi, Saitama 332-0012, Japan
}

\begin{abstract}
Fluorescence in situ hybridization (FISH) is a powerful tool used in karyotyping, cytogenotyping, cancer diagnosis, species specification, and gene-expression analysis. Although widely used, conventional FISH protocols are cumbersome and time consuming. We have now developed a FISH method using exciton-controlled hybridization-sensitive fluorescent oligodeoxynucleotide (ECHO) probes. ECHO-FISH uses a 25-min protocol from fixation to mounting that includes no stringency washing steps. We use ECHO-FISH to detect both specific DNA and RNA sequences with multicolor probes. ECHO-FISH is highly reproducible, stringent, and compatible with other fluorescent cellular labeling techniques. The resolution allows detection of intranuclear speckles of poly(A) RNA in HeLa cells and dissociated hippocampal primary cultures, and mRNAs in the distal dendrites of hippocampal neurons. We also demonstrate detection of telomeric and centromeric DNA on metaphase mouse chromosomes. The simplicity of the ECHO-FISH method will likely accelerate cytogenetic and gene-expression analysis with high resolution.
\end{abstract}

Keywords: probe; RNA; FISH; excitonic interaction; thiazole orange

\section{INTRODUCTION}

Fluorescence in situ hybridization (FISH) analysis offers high-resolution detection of specific DNA and RNA in individual cells. DNA-FISH has found wide applications in karyotyping, cytogenotyping, cancer diagnosis, and species specification (Lichter et al. 1988; Schrock et al. 1996; Trask 2002; Klonisch et al. 2010; Horbinski et al. 2011). RNAFISH analysis provides information about tissue-specific, cell-specific, and subcellular gene expression at different developmental stages of an organism, and thus has been used to analyze gene expression in great detail. FISH probes were first developed in the late 1970s (Rudkin and Stollar 1977; Bauman et al. 1980; Singer and Ward 1982), but numerous technical advancements have since been made in

\footnotetext{
${ }^{5}$ Corresponding authors.

E-mail dwang@icems.kyoto-u.ac.jp.

E-mail aki-okamoto@riken.jp.

Article published online ahead of print. Article and publication date are at http://www.rnajournal.org/cgi/doi/10.1261/rna.028431.111.
}

the engineering of FISH probes and protocols (Langer et al. 1981; Nielsen et al. 1991; Nilsson et al. 1994; Femino et al. 1998; Silahtaroglu et al. 2004; Larsson et al. 2010). New protocols allow a range of detection methods (Manuelidis et al. 1982; van de Corput et al. 1998; Sharpe et al. 2002), multiplex detection (Speicher et al. 1996; Levsky et al. 2002), highly sensitive quantitative measurement (Femino et al. 1998; Raj et al. 2008), and fabrication of microfluidic devices for integration of data collection and analysis (Sieben et al. 2008). Continuous efforts have significantly improved the signal-to-noise ratio, sensitivity, and reproducibility of FISH in various applications. In contrast, little technical advancement has been achieved in simplifying the procedure. Although robotic platforms have been developed at the state-of-the-art facilities (Gong et al. 2003; Lein et al. 2007), FISH remains a labor-intensive and time-consuming technique and the technical complexity of current protocols hampers their general utilization in both academia and clinical sectors.

To simplify conventional FISH protocols, we now have developed a target-dependent fluorescent turn-on method 
by adapting ECHO probes to perform both RNA- and DNA-FISH (ECHO-FISH). Compared with conventional FISH probes that are labeled with fluorophores or haptens (fluorescein, cy3, cy5, biotin, DIG, etc.), ECHO probes contain a single thymine or cytosine base labeled with a homodimer of thiazole orange (TO, 4-[3-methyl-2,3-dihydro(benzo-1,3-thiazole)-2-methyllidene] quinolinium iodid). (Ikeda and Okamoto 2008). TO is characterized by a large fluorescent enhancement upon intercalation into nucleic acids, and has been extensively used in reticulocyte analysis and DNA staining (Lee et al. 1986). The binding affinity of TO to DNA and its photophysical properties have been previously studied (Rye et al. 1992; Netzel et al. 1995).

Compared with TO monomers, the fluorescence of TO homodimers is further suppressed due to the excitonic coupling between the two TO chromophoric units, which strongly inhibits photon release from the excited TO (Schins et al. 1999). Upon hybridization, bis-intercalation of TO into the double-stranded nucleic acids both substantially reduces the interchromophoric interaction and meanwhile restricts the rotation around the methine bond of TO, resulting in robust fluorescent emission from both TO dyes (Nygren et al. 1998). We designated the thymine or cytosine labeled with TO homodimer as "D514" for doubly labeled dyes with an excitation maximum at $514 \mathrm{~nm}$ (Ikeda and Okamoto 2008).

In the new protocol, linear oligodeoxynucleotide (ODN) probes containing D514 are used to convey recognition of the specific DNA or RNA. Because of the low-fluorescent emission of the unhybridized probes and the robust fluorescence activation upon hybridizing to target RNA or DNA, no prehybridization or stringency washes are required to decrease background signals. The binding of TO adds thermal stability to the probe:DNA/RNA duplex, indicated by a $7^{\circ}-9^{\circ} \mathrm{C}$ increase in $\mathrm{T}_{\mathrm{m}}$ for 13 -nt probes (Ikeda and Okamoto 2008). The synthesis of D514 probes is inexpensive and facile with standard ODN synthesis and reversephase HPLC purification (Ikeda and Okamoto 2008).

Here we demonstrate multicolor, target-specific FISH signals of specific RNA and DNA sequences obtained with a significantly simplified protocol. The ECHO-FISH protocol is highly compatible with other fluorescent cellular labeling techniques, which allows analysis of gene expression in specific cell types and in specific subcellular compartments.

\section{RESULTS}

\section{Hybridization-sensitive fluorescence activation of D514 FISH probes}

We first set out to test whether fluorescence emission of D514 probes can be activated by specific nucleic acids. For this purpose, we synthesized TTTTTTD514TTTTTT $\left(\mathrm{T}_{6} \mathrm{D}_{514 \mathrm{~T}_{6}}\right)$ and CGCAATD514TAACGC (CGCD514), and measured their emission spectra in the presence of comple- mentary or noncomplementary single-stranded DNA. The chemical structure of D514 and the concept of hybridization-dependent emission are illustrated in Figure 1, A and B. Both $\mathrm{T}_{6} \mathrm{D}_{514 \mathrm{~T}_{6}}$ and CGCD514 probes emitted little fluorescence in the presence of noncomplementary DNA, as indicated by an overlapping spectrum with probe alone control. However, both probes showed sharp fluorescence activation in the presence of their complementary DNA (Fig. 1C). Disrupting hybridization between probes and complementary DNA with $50 \%$ formamide effectively inhibited fluorescence emission, indicating that the fluorescence activation is hybridization sensitive (Fig. 1D).

The fluorescence activation was quantified as $F_{\text {on }} / F_{\text {off }}$ $\left(F_{\text {on }}\right.$ : total probe fluorescence intensity $[520-555 \mathrm{~nm}]$ in the presence of complementary DNA; $F_{\text {off }}$ : total fluorescence intensity $[520-555 \mathrm{~nm}]$ of probes before hybridization). We then tested whether D514 probes can detect specific RNA targets in highly heterologous RNA populations. For this purpose, we extracted total RNA from rat brain and separated the total RNA into poly(A) RNA-enriched and poly(A) RNA-depleted fractions using oligo $\mathrm{d}(\mathrm{T})_{30}$-latex. The $\mathrm{T}_{6} \mathrm{D}_{514} \mathrm{~T}_{6}$ probe was turned on by both the total RNA and the poly(A) RNA-enriched fraction. However, the fluorescence emission was significantly suppressed by the poly(A) RNA-depleted fraction. In contrast, the fluorescence emission of $\mathrm{A}_{6} \mathrm{D}_{514 \mathrm{~A}_{6}}$ (AAAAAAD514AAAAAA) was low in all three groups with no significant difference from each other, indicating that $\mathrm{T}_{6} \mathrm{D} \mathrm{D}_{4} \mathrm{~T}_{6}$ specifically detected poly(A) RNA in the extracted total RNA (Fig. 1E). $A_{6} D 514 A_{6}$ became highly fluorescent when mixed with $\mathrm{d}(\mathrm{T})_{13}$, indicating that its low emission in the presence of total RNA is likely due to the low abundance of targets (Supplemental Fig. S1A). The source of the fluorescence activation of D514 probes was confirmed by the absorption spectra, where an absorption band-shift from 480 to 510 $\mathrm{nm}$ (when TO homodimers become monomers upon hybridization) was observed in the presence of the complementary DNA (Supplemental Fig. S1B).

To test whether $F_{\text {on }} / F_{\text {off }}$ can serve as a quantitative measurement of the concentration of target DNA or RNA, we measured the emission spectrum of $T_{6} D_{514 T_{6}}$ in the presence of polyadenylic acid between $10^{-7}$ and $10^{-2}$ $\mathrm{M}$ of base concentration. $F_{\text {on }} / F_{\text {off }}$ of $\mathrm{T}_{6} \mathrm{D} 14 \mathrm{~T}_{6}$ linearly correlated to the concentration of polyadenylic acid between $10^{-6}$ and $10^{-3} \mathrm{M}$, a physiological concentration range of poly(A) in human lymphocytes (Krug and Berger 1986). Consistent with the spectral results measured using $\mathrm{T}_{6} \mathrm{D}_{514 \mathrm{~T}_{6}}, F_{\text {on }} / F_{\text {off }}$ of three other gene-specific ECHO probes were also dependent on the concentrations of the target DNA, indicating that such calibration curves may be used to determine unknown concentrations of target RNA or DNA (Fig. 1F).

We have previously shown that the ODN sequences at or neighboring D514 play important roles in fluorescent activation by directly interacting with TO (Ikeda et al. 


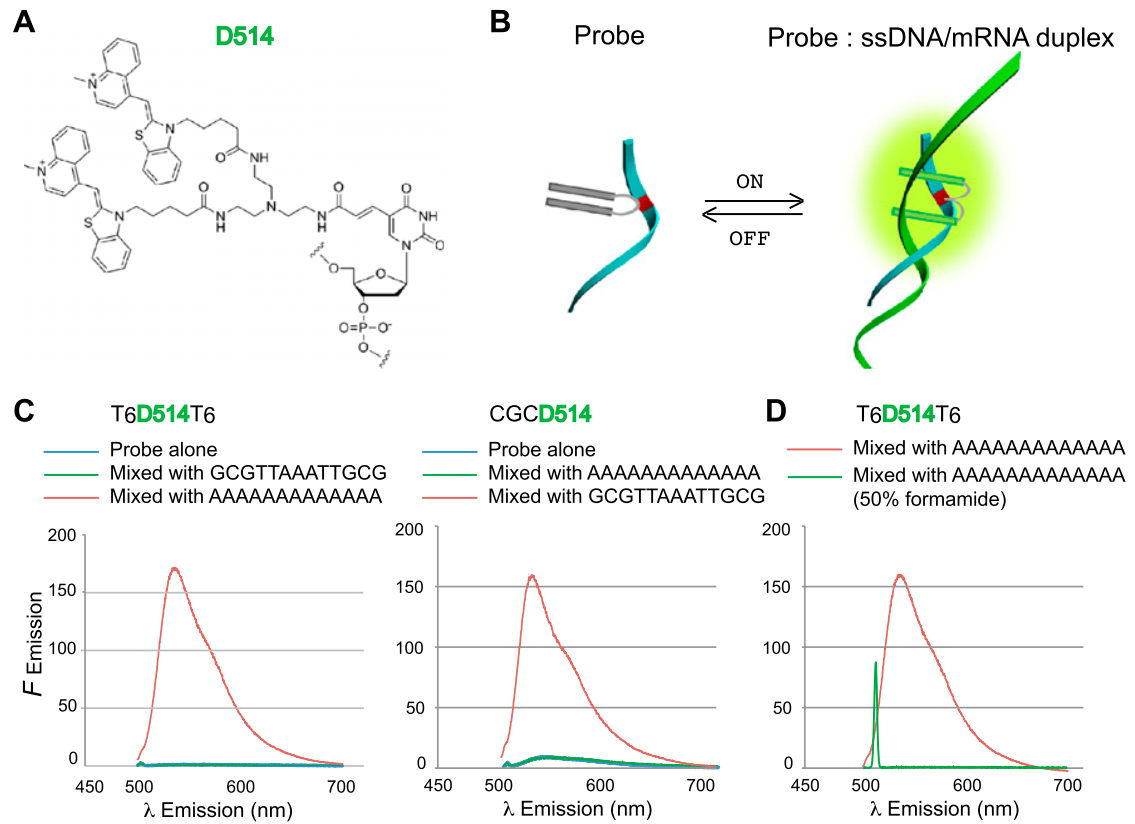

E
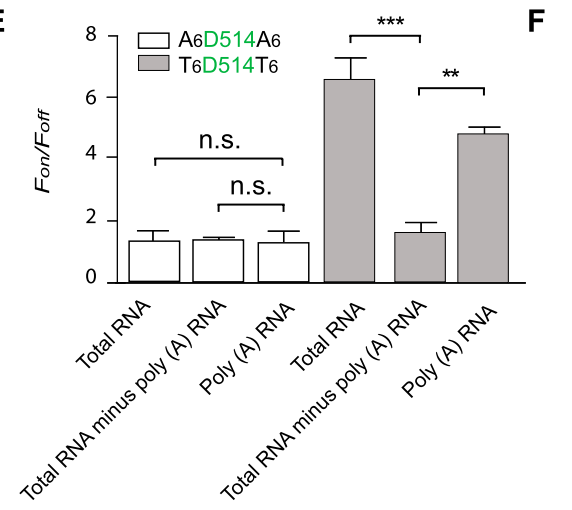

FIGURE 1. Hybridization-sensitive fluorescence of D514 probes. (A) Chemical structure of D514 with two thiazole orange dyes covalently linked to a thymine through a diamidite linker. (B) Illustrative model of the reversible fluorescent switch of D514 probes upon hybridization and dissociation to the complementary ssDNA or RNA (blue ribbon: probe oligo; red square: thymidine; gray squares: quenched TO homodimer; green ribbon: target RNA or ssDNA; green squares: intercalated fluorescent TO monomers). (C) Emission spectra (500-700 nm) of $\mathrm{T}_{6} \mathrm{D}_{14} \mathrm{~T}_{6}$ and CGCD514 $(0.5 \mu \mathrm{M})$ measured in PBS $\left(\mathrm{pH} 7.4,25^{\circ} \mathrm{C}\right)$. Blue line, probes alone; green line, with noncomplementary DNA $(0.25 \mu \mathrm{M})$; red line, with complementary DNA $(0.25$ $\mu \mathrm{M}) .(D)$ Emission spectra of $\mathrm{T}_{6} \mathrm{D} 514 \mathrm{~T}_{6}$ in the presence of complementary DNA with (green) or without $50 \%$ formamide (red). (E) $\mathrm{F}_{\text {on }} / \mathrm{F}_{\text {off }}$ ratio of $\mathrm{T}_{6} \mathrm{D} 514 \mathrm{~T}_{6}$ and $\mathrm{A}_{6} \mathrm{D}_{514 \mathrm{~A}_{6}}(2 \mathrm{ng} / \mathrm{uL}$ ) hybridized to total RNA extracted from rat brain $(20 \mathrm{ng} / \mu \mathrm{L}$, probe to sample ratio: $1: 10)$, mRNA-depleted total RNA (17 ng/ $\mu \mathrm{L}$, probe to sample ratio: $1: 8.5)$, poly(A) RNA $(0.8 \mathrm{ng} / \mu \mathrm{L}$,

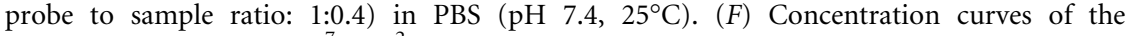
complementary DNA $\left(10^{-7}-10^{-2} \mathrm{M}\right)$ detected by $\mathrm{T}_{6} \mathrm{D} 514 \mathrm{~T}_{6}\left(0.2 \mu \mathrm{M}\right.$ in PBS, $\left.25^{\circ} \mathrm{C}\right)$ and three gene-specific probes $\left(0.2 \mu \mathrm{M}\right.$, in hybridization buffer containing $25 \%$ formamide, $\left.25^{\circ} \mathrm{C}\right)$. Trendlines were fitted using the red data points where linear correlation was observed (outlier data points are in blue).

2008). To test whether these sequences can be used to sensitively detect subtle sequence differences such as polymorphism variants, we measured the fluorescence emission of three gene-specific probes in the presence of DNA containing single or double mismatches (Supplemental Fig. S2). Substitution of the adenine that base pairs with

D514 to $\mathrm{N}$ ( $\mathrm{N}$ was $\mathrm{C}, \mathrm{G}$, or $\mathrm{T}$ ) significantly decreased fluorescent turn-on to $38 \%-68 \%$ of the value using complementary DNA. Double mismatches neighboring D514 (up to 3 nt away) resulted in a decrease of the ON/OFF ratio to $21 \%-72 \%$, indicating that minor imperfections in target sequences can be detected by effectively designed D514 ECHO probes (Supplemental Fig. S2). It is noteworthy that the emission of the probes in the presence of mismatched DNA did exceed background $\left(F_{\text {on }} / F_{\text {off }}\right.$ was larger than 1$)$, indicating that the discrimination ability is limited.

\section{ECHO-FISH with $\mathrm{T}_{6} \mathrm{D}_{514 \mathrm{~T}_{6}}$ probes detects poly(A) RNA in HeLa cells and primary hippocampal cultures with high stringency}

Encouraged by the robust fluorescent activation of D514 probes, we developed a FISH protocol that includes three simple steps (fixation, permeabilization, and hybridization) before imaging (Fig. 2A). We first applied this protocol to detect poly(A) RNA in HeLa cells. After a quick fixation and permeabilization, we applied $\mathrm{T}_{6} \mathrm{D}_{514 \mathrm{~T}_{6}}(200 \mathrm{nM})$ to the cells in the presence of $10 \%$ formamide (see Materials and Methods for more details). Robust FISH signals were immediately observed upon application of $\mathrm{T}_{6} \mathrm{D} 14 \mathrm{~T}_{6}$, with the characteristic poly $(\mathrm{A})$ RNA localization pattern previously reported in HeLa cells. $\mathrm{A}_{6} \mathrm{D}_{514 \mathrm{~A}_{6}}$ revealed $\operatorname{dim}$ FISH signals under the same conditions (Fig. 2B). The hybridizationsensitive fluorescence of D514 allowed us to observe the dynamic hybridization process. When applied at room temperature, we observed robust fluorescent signals immediately after applying the $\mathrm{T}_{6} \mathrm{D}_{514} \mathrm{~T}_{6}$, which increased in the next $30 \mathrm{~min}$. Incubation up to $72 \mathrm{~h}$ did not result in higher signal or background level, indicating high stability and integrity of the probes.

To compare the probe behavior to conventional FISH probes, we synthesized and applied $\mathrm{Cy} 5-\mathrm{d}(\mathrm{T})_{13}$ in parallel experiments. Cy5-d $(\mathrm{T})_{13}$ revealed noisy images with no poly(A) RNA localization pattern to be recognized. We then synthesized Cy5-d $(T)_{30}$ to increase the $T_{m}$. Cy5-d $(T)_{30}$ did reveal FISH signals; however, the background was very 
A
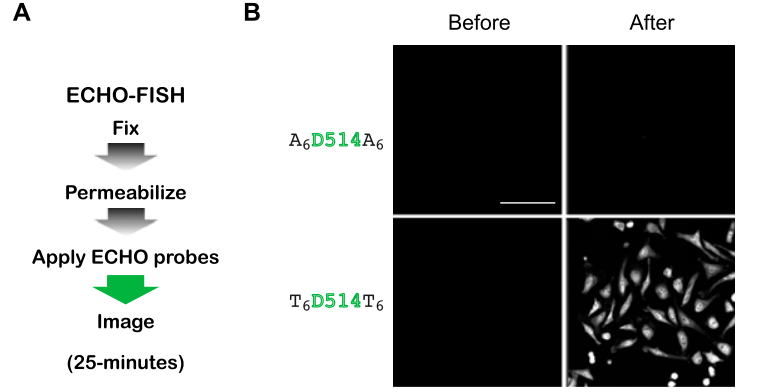

C

C TTTTTTD514TTTTтT

b TTTTTTCD514TTTTTT

c TTTTTAD514ATTTTT

d TTTTTCD514CTTTTT

e TTTTTGD514GTTTTT

f TTTTGTD514TGTTT

g TTTGTTD514TTGTT

h TTGTTD514TTTGTT
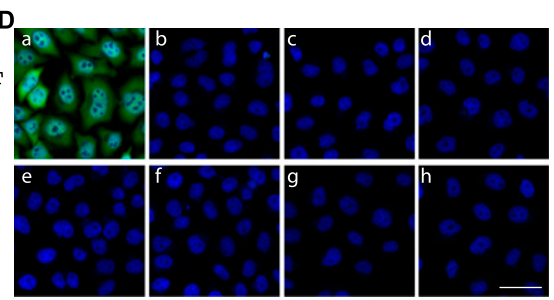

E

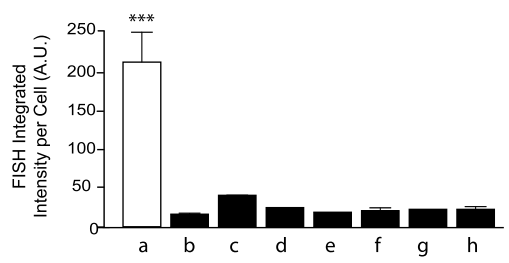

FIGURE 2. Detection of poly(A) RNAs in HeLa cells with high stringency. (A) The flowchart of the three-step ECHO-RNA FISH protocol. $(B)$ Confocal images of HeLa cells probed by $\mathrm{T}_{6} \mathrm{D}_{514 \mathrm{~T}_{6}}$ and $\mathrm{A}_{6} \mathrm{D}_{514 \mathrm{~A}_{6}}$ immediately before and after probe applications. Scale bar, $100 \mu \mathrm{m}$. (C) Sequences of mutated $\mathrm{T}_{6} \mathrm{D}_{514 \mathrm{~T}_{6}}$ probes with single or double mismatches. Italic bold, nucleotides that thymidines are mutated to. (D) Confocal images of HeLa probed by wild-type $\mathrm{T}_{6} \mathrm{D} 14 \mathrm{~T}_{6}(a)$ and mutant probes $(b-h)$ and counterstained with DAPI. Scale bar, $25 \mu \mathrm{m}$. (E) Quantification of 2D as integrated FISH intensity per cell (arbitrary units, MEAN $\pm \mathrm{SD}$ ). Data from three independent experiments were pooled for statistical analysis. One-way ANOVA was performed followed by Dunnett's multiple comparisons to $a(P<0.0001)$.

noisy (Supplemental Fig. S3A). When conventional FISH protocols were applied, Cy5-d(T) $)_{30}$ detected a characteristic poly(A) RNA distribution pattern consistent with previous reports. When $\mathrm{T}_{6} \mathrm{D} 514 \mathrm{~T}_{6}$ was co-applied with $\mathrm{Cy} 5-\mathrm{d}(\mathrm{T})_{30}$ in the conventional protocol, or when $\mathrm{T}_{6} \mathrm{D} 14 \mathrm{~T}_{6}$ was applied after conventional FISH procedure with Cy5$\mathrm{d}(\mathrm{T})_{30}$, we detected colocalized FISH signals; however, the punctated nuclear speckle pattern revealed by $\mathrm{T}_{6} \mathrm{D}_{514 \mathrm{~T}_{6}}$ appeared less prominent than $\mathrm{Cy} 5-\mathrm{d}(\mathrm{T})_{30}$ (Supplemental Fig. S3B). When $\mathrm{T}_{6} \mathrm{D} 514 \mathrm{~T}_{6}$ was applied alone using the ECHO-FISH protocol, prominent nuclear speckles indistinguishable from that revealed by $\mathrm{Cy} 5-\mathrm{d}(\mathrm{T})_{30}$ using a conventional FISH protocol were observed (Supplemental Fig. S3C).

To test the stringency of the fluorescent signals, we introduced single or double mismatch nucleotides in the $\mathrm{T}_{6} \mathrm{D} 514 \mathrm{~T}_{6}$ probes to disrupt their complementarity to poly(A). We introduced a single mutation at the center thymidine to be substituted by cytidine, and a series of double mutations around D514 (Fig. 2C). In all of these cases, FISH signals were diminished, indicating that complete complementarity is required for detecting poly(A) using ECHO-FISH (Fig. 2D,E). Fluorospectral measurement of each mutated probe confirmed that all mutant probes were successfully turned on by complementary DNA, indicating that the diminished fluorescence was not caused by the photophysical failures of the mutant probes (Supplemental Fig. S4). The diminished FISH signals suggest that the new protocol detects target RNA with high stringency.

To further test detection specificity and resolution, we turned to dissociated rat hippocampal cultures due to their high cell population heterogeneity and discrete subcellular compartments of hippocampal neurons. When applied to the P0/DIV14 hippocampal cultures (cultures prepared from postnatal day 0 rat pups and allowed to develop for $14 \mathrm{~d}$ in vitro), $\mathrm{T}_{6} \mathrm{D} 514 \mathrm{~T}_{6}$ revealed robust fluorescent signals in the nucleus, soma, and distal processes of hippocampal cells (Supplemental Fig. S5). $\mathrm{A}_{6} \mathrm{D}_{514 \mathrm{~A}_{6}}$ revealed negligible fluorescence, while CGCD514 showed no fluorescence higher than the no-probe control. This result is consistent with the abundance of target RNAs in hippocampal cells that the three probes complement: targets for $\mathrm{T}_{6} \mathrm{D} 514 \mathrm{~T}_{6}$, including all poly(A) RNAs, are most abundant; targets for

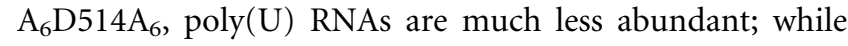
CGCD514 does not have apparent complementary targets predicted by BLAST search.

\section{The ECHO-FISH protocol is compatible with other fluorescent cellular labeling techniques}

To test compatibility of the ECHO-FISH protocol with other fluorescent labeling techniques, we stained hippocampal cultures with a panel of antibodies (MAP2, GFAP, and synaptophysin) or with fluorescent phalloidin, followed by ECHO-FISH. Immunofluorescence labeling did not affect ECHO-FISH signals or vice versa (Supplemental Fig. S6A). We then transfected hippocampal cultures with mStrawberry, a red-orange FP (Ex: $574 \mathrm{~nm}$, Em: $596 \mathrm{~nm}$ ), fixed the cells and performed ECHO-FISH. We detected both the ECHO-FISH signal and the mStrawberry fluorescence signal with no interference between the two, demonstrating that ECHO-FISH is also compatible with genetically coded fluorescent cell labeling techniques (Supplemental Fig. S6B).

\section{ECHO-FISH detects gene-specific transcripts}

To test whether we could detect gene-specific transcripts using ECHO-FISH, we synthesized 21 probes against six genes (CaMKII $\alpha$, Stmn1, Tubb2b, GAPDH, Npas4, and Nr4a1) as well as 21 negative control probes with scrambled sequences (Supplemental Table 1). The probe sequences 
were designed to achieve highly suppressed fluorescent emission in the absence of their target RNA, based on our previous characterizations on the sequence-dependent quenching efficiency of D514 probes (Ikeda et al. 2008). We particularly avoided sequences that can form stable self-dimers neighboring D514, which induce poor quenching efficiency. After the probes were synthesized, their dark state before hybridization and sufficient fluorescent turn-on by complementary DNA were confirmed using spectrofluorometry. Using $\mathrm{T}_{6} \mathrm{D} 14 \mathrm{~T}_{6}$ as a positive control, we applied the 42 probes (21 negative control probes and 21 gene-specific probes) to DIV14-dissociated hippocampal cultures using the ECHO-FISH protocol and quantified FISH signals as mean fluorescent intensity per cell. After optimizing probe concentrations, hybridization temperature, and the composition of the hybridization buffer, very low background signals were detected in the samples probed by the negative control probes compared with the noprobe control (Fig. 3A,B). D514 probes having the TO homodimer labeled at their $5^{\prime}$-ends (negative control 15-17) did not result in aberrant background signals. Under the same experimental conditions, many of the gene-specific probes showed significantly higher FISH signals, especially the probes against CaMKII $\alpha$ and Tubb2b, consistent with their abundance in rodent primary hippocampal cultures (Fig. 3A,B). To further test the specificity of the signals detected by probes against CaMKII $\alpha$, Tubb2b, and Nr4al, we synthesized and applied D514 sense probes where little FISH signal was detected (Fig. 3C).

The four CaMKII $\alpha$-specific probes detected FISH signals in the cytoplasm of neurons with different fluorescent intensities, which may reflect different hybridization efficiency and/or binding modes of TO (Fig. 3A,B). We then took advantage of the populational heterogeneity of the dissociated hippocampal cultures and compatibility of ECHOFISH with immunofluorescence labeling techniques to test whether CaMKII $\alpha$ FISH signals were selectively detected in cell populations endogenously expressing CaMKII $\alpha$ protein. We costained the cultures with a monoclonal CaMKII $\alpha$

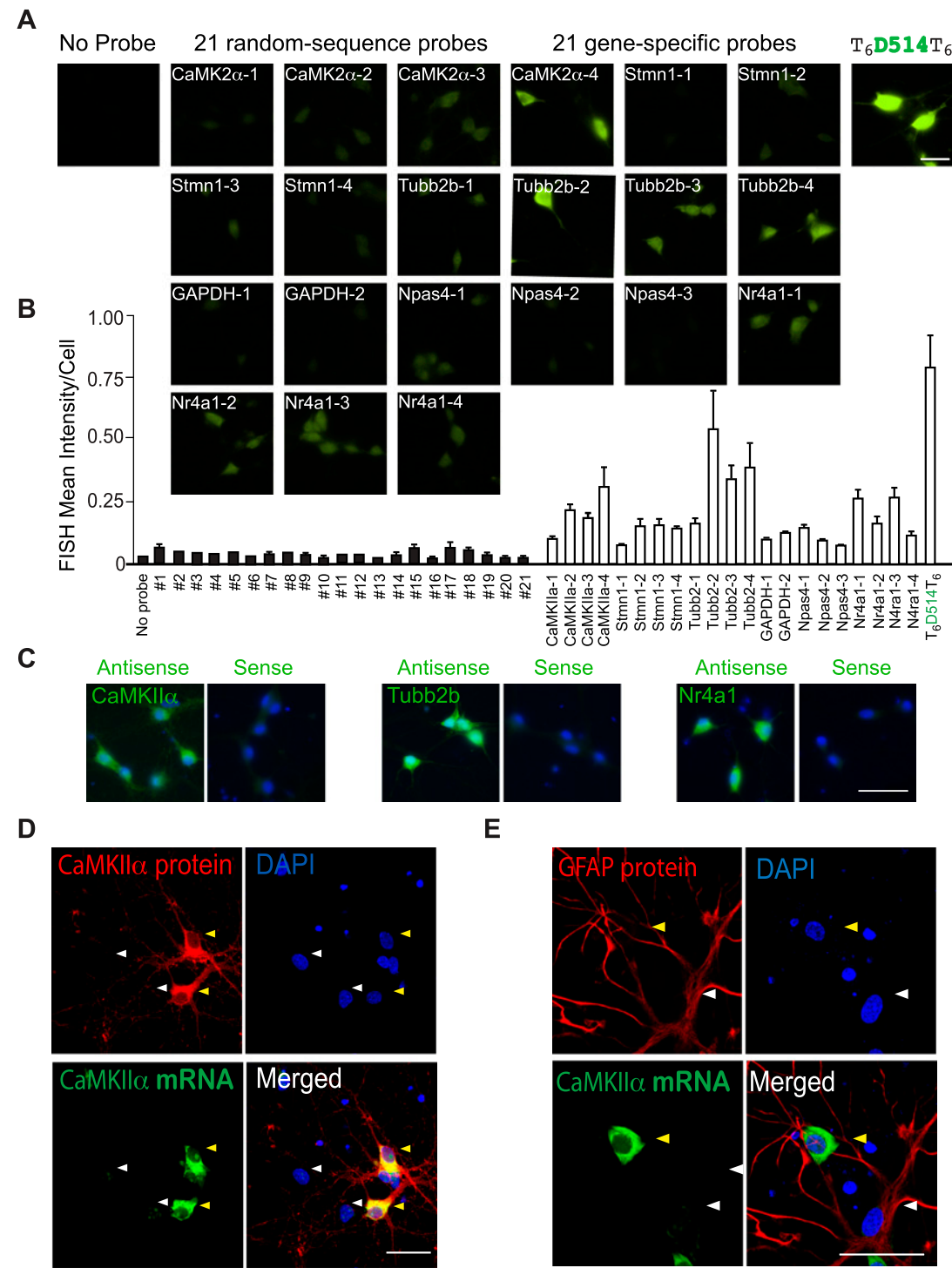

FIGURE 3. Detection of gene-specific transcripts in primary hippocampal cultures. $(A)$ Epifluorescence micrographs of DIV14 rat primary hippocampal cultures probed by 21 genespecific probes with $\mathrm{T}_{6} \mathrm{D} 514 \mathrm{~T}_{6}$ as the positive control. Scale bar, $30 \mu \mathrm{m}$. (B) Quantification of ECHO-FISH intensity for each tested probe including 21 negative control probes; $y$-axis, mean intensity of FISH signal per cell (MEAN \pm SD). (C) Epifluorescence images of DIV14 rat primary hippocampal cultures probed by transcript-specific antisense probes (green, left), sense probes (green, right), and counterstained with DAPI (blue). Scale bar, $25 \mu \mathrm{m}$. (D) Confocal micrographs of DIV 14 primary hippocampal cultures that were costained with CaMKII $\alpha$ antibodies (red), DAPI (blue) while probed with pooled CaMKII $\alpha$ probes (green). Robust FISH signals were detected in CaMKII $\alpha$-immunoreactive cells (yellow arrowheads) but lacking in neighboring CaMKII $\alpha$-nonimmunoreactive cells (white arrowheads). Scale bar, $25 \mu \mathrm{m}$. (E) Confocal micrographs of DIV 14 primary hippocampal cultures costained with the GFAP antibody (red), DAPI (blue), while probed with pooled CaMKII $\alpha$ probes (green). GFAP-positive glial cells lacked FISH signals (white arrowheads), which were abundant in a neighboring cell that is most likely to be neuronal (yellow arrowheads). Scale bar, $25 \mu \mathrm{m}$. antibody and applied the four CaMKII $\alpha$ probes (pooled). We observed robust, yet restricted FISH signals to cells whose immunoreactivity to CaMKII $\alpha$ antibody was positive (Fig. 3D). In contrast, $\mathrm{T}_{6} \mathrm{D}_{14} \mathrm{~T}_{6}$ detected comparable FISH signals between CaMKII $\alpha$-positive and CaMKII $\alpha$ negative cell populations (Supplemental Fig. S7A). We then 
costained the hippocampal cultures with a GFAP (glial fibrillary acidic protein, a glia marker) antibody and found little, if any, CaMKII $\alpha$ FISH signals in GFAP-positive glial cells (Fig. 3E, white arrowheads). In contrast, the neighboring cells that are most likely to be neuronal showed robust FISH signals (Fig. 3E, yellow arrowheads). This distinction is not due to an overall low transcriptional activity in glia, since $\mathrm{T}_{6} \mathrm{D} 14 \mathrm{~T}_{6}$ revealed similar levels of FISH signal in both GFAP-positive and GFAP-negative cells (Supplemental Fig. S7B). This result is consistent with previous findings on the differential expression of CaMKII $\alpha$ mRNA in neurons of hippocampus (Burgin et al. 1990).

\section{The resolution of ECHO-FISH allows subcellular detection}

Consistent with previous characterization of poly(A) RNA, $\mathrm{T}_{6} \mathrm{D}{ }_{14} \mathrm{~T}_{6}$ successfully recapitulated their localization pattern such as intranuclear speckles in both HeLa cells and in dissociated hippocampal cultures (Figs. 2A, 4A). The shape, size, and number of puncta per cell varied among cells and so did the cytoplasm/nucleus distribution of poly(A) RNA FISH intensity. In contrast, CaMKII $\alpha-$, Tubb2b-, and Nr4a1-specific probes revealed predominantly cytoplasmic distribution of the target RNA (Fig. 4B). ECHO-FISH using $\mathrm{T}_{6} \mathrm{D}_{514 \mathrm{~T}_{6}}$ probe also detected poly(A) RNA inside neuronal processes labeled by fluorescent phalloidin and at

A

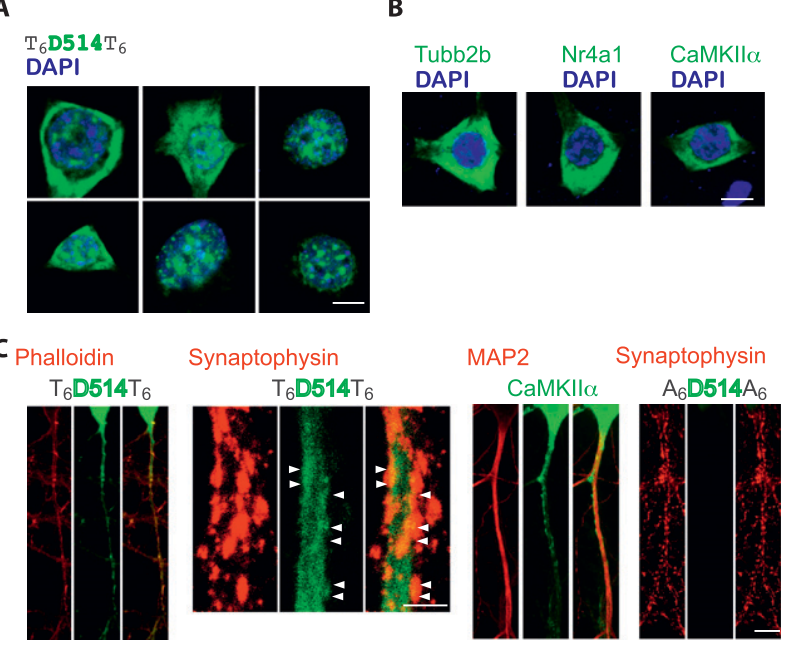

FIGURE 4. ECHO-FISH reveals poly(A) RNA nuclear speckles and dendritically localized mRNA. (A) Confocal micrographs of soma of DIV14 rat hippocampal cultures probed with $\mathrm{T}_{6} \mathrm{D}_{514 \mathrm{~T}_{6}}$ while counterstained with DAPI. Diverse nuclear speckle patterns were observed in the heterogeneous cell population. Scale bar, $5 \mu \mathrm{m}$. (B) Confocal micrographs of soma of DIV14 rat hippocampal cultures probed with D514 probes against CaMKII $\alpha$, Tubb2b, and Nr4a-1 while counterstained with DAPI. Scale bar, $5 \mu \mathrm{m}$. (C) Confocal micrographs of DIV14 primary hippocampal cultures costained with phalloidin, synaptophysin, MAP2 antibodies (red), and D514 probes (green). White arrowheads point to post-synaptic contacting sites opposing synaptophysin-positive clusters. Scale bars, 8 and $2 \mu \mathrm{m}$. post-synaptic contacting sites opposing to synaptophysinpositive clusters (Fig. 4C). The cytoplasmic FISH signals detected by CaMKII $\alpha$-specific probes extended into the distal dendrites, consistent with previous findings that CaMKII $\alpha$ mRNA is transported into dendrites and locally translated (Fig. 4C; Benson et al. 1992). Sense-control probe $\mathrm{A}_{6} \mathrm{D} 514 \mathrm{~A}_{6}$ revealed dim signals compared with $\mathrm{T}_{6} \mathrm{D}_{1414 \mathrm{~T}_{6}}$. These demonstrations suggest that the ECHOFISH protocol achieves high enough resolution to study subcellular localization of RNAs.

\section{Multicolor detection of poly(A) RNA in dissociated hippocampal cultures}

To allow multicolor detection, we applied $\mathrm{T}_{6} \mathrm{DnnnT}_{6}(\mathrm{nnn}=$ $488,514,570,600,640,715)$ probes described in Ikeda et al. $(2009,2011)$ to detect poly(A) RNA in dissociated hippocampal cultures. $\mathrm{T}_{6} \mathrm{DnnnT}_{6}$ probes with distinct excitation and emission spectrum all detected poly(A) RNA FISH signals with the characteristic nuclear speckle localization pattern (Fig. 5).

\section{Telomere, minor satellite, and major satellite DNA-specific D514 probes detect specific regions of chromosomes in mouse ES cells}

Finally, to apply the ECHO-FISH protocol to perform DNA-FISH, we synthesized D514 probes complementary to the repetitive DNA sequences in mouse telomere, minor satellite, and major satellite chromosomal regions (Fig. 6A). We then applied these probes using a simplified DNAFISH protocol to metaphase chromosomal spreads prepared from mouse ES cells (Fig. 6B). Telomere DNAspecific D514 probes detected four distinct puncta located at the ends of the metaphase chromosomes. D514 probes specific to minor and major satellite DNA detected two and one punctum, respectively, that are located to the centromeric and pericentromeric regions (Fig. 6C). These strikingly discrete localization patterns detected by ECHOFISH are highly consistent with previous characterization of these subchromosomal regions (Guenatri et al. 2004). The DNA-FISH protocol we used, however, excluded prehybridization and all washing steps after hybridization, yielding a much simplified and time-efficient protocol (Fig. 6B).

\section{DISCUSSION}

Current FISH technology is powerful, but time-consuming and labor-intensive, relying on stringency washes to reduce fluorescence background. The sources for the background noises can be the partial or nonspecific hybridization to nucleic acids, the inadvertent sticking of probes to the cellular matrix, and/or nonspecific binding of reagents used for secondary amplification steps (e.g., streptavidin, antibodies). The advance described herein is to take advantage 


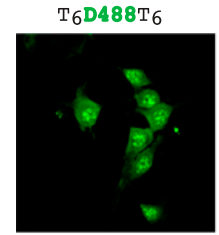

T6D600T6

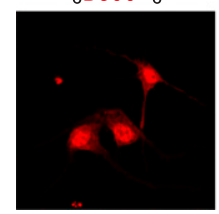

$\mathrm{T} 6 \mathrm{D} 51 / \mathrm{T} 6$

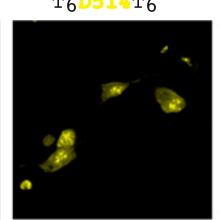

$\mathrm{T} 6 \mathrm{D} 640 \mathrm{~T} 6$

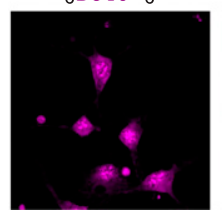

T6D570T6

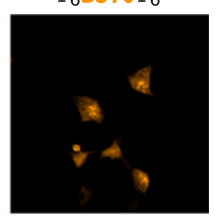

T6D715T6

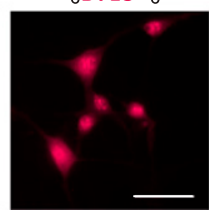

FIGURE 5. ECHO-FISH using multicolor poly(A) probes. Confocal micrographs of DIV14 rat hippocampal cultures probed with $\mathrm{T}_{6} \mathrm{D}_{488 \mathrm{~T}_{6}}, \mathrm{~T}_{6} \mathrm{D} 514 \mathrm{~T}_{6}, \mathrm{~T}_{6} \mathrm{D}_{570 \mathrm{~T}_{6}}, \mathrm{~T}_{6} \mathrm{D}_{600 \mathrm{~T}}$, and $\mathrm{T}_{6} \mathrm{D}_{640 \mathrm{~T}_{6}}$, and epifluorescent micrograph of DIV14 rat hippocampal cultures probed with $\mathrm{T}_{6} \mathrm{D}_{715 \mathrm{~T}_{6}}$. Scale bar, $25 \mu \mathrm{m}$.

of the photochemical properties of thiazole orange dyes and incorporate them into FISH probes whose fluorescent emission is strictly dependent on the local hybrid structure of probe:target (Ikeda and Okamoto 2008). Adapting the novel photochemical probes greatly improves the time and labor efficiency of the conventional FISH procedure, since prehybridization, stringency washes, and secondary detection steps can be eliminated from the protocol without compromising the detection fidelity.

Using the new protocol with D514-labeled linear oligo probes of 13-21 nt, we demonstrate detection of both poly(A) RNA and gene-specific transcripts in $25 \mathrm{~min}$. Single target was predicted by blasting probe sequences against NCBI databases before synthesis. The simplicity of the new protocol offers excellent compatibility with other fluorescent cellular labeling techniques such as immunofluorescence labeling, cellular tracker staining, and fluorescent protein labeling, which in turn allows examination of FISH specificity with codetection of the target protein.

We provide four lines of evidence to demonstrate detection specificity: (1) single mismatches in D514 probes diminish FISH signals; (2) sense control probes reveal only background FISH signals; (3) cellular distribution pattern of FISH signals is consistent with the immunostaining pattern of the target protein; and (4) discrete localization patterns of poly(A) RNA in nuclear speckles, and telomere, minor satellite, and major satellite on chromosomes are consistent with previous reports. Due to the small size of D514 probes (13-50
A Telomere: CCCTAACCCD514AACCCTAA
Minor Satellite: CGTATGTGTTTD514TCAGTGT
Major Satellite: TGACGAAAD514CAAAAAACGT

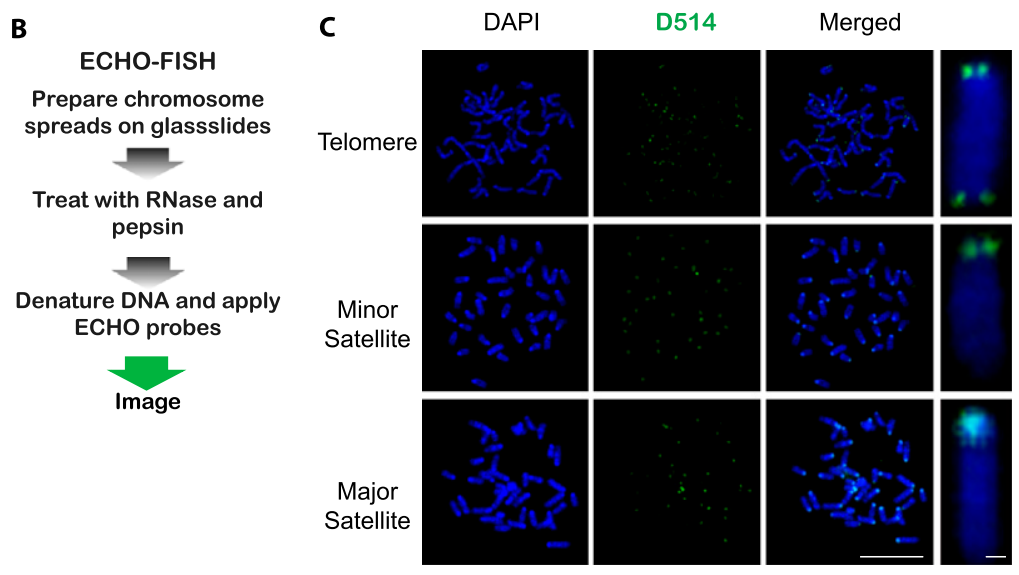

FIGURE 6. Detection of telomere, minor satellite, and major satellite DNA in mouse ES cells. (A) Sequences of D514 probes to detect the corresponding DNA regions. (B) The flowchart of ECHO-DNA FISH. (C) Confocal micrographs of mouse ES chromosomes hybridized with D514 probes specific to telomeric DNA (top), minor satellite DNA (middle), and major satellite DNA (bottom) with DAPI counterstaining. Merged images from a pair of sister chromosomes are shown in high magnification to reveal the localization of each chromosomal region detected with ECHO-FISH. Scale bars, $20 \mu \mathrm{m}$ in the low-magnification images and $1 \mu \mathrm{m}$ in the high-magnification images. 
hancement systems can also contribute to lowering the detection limit.

With each cell possessing an intact genome, the demand on gene-expression profiling in individual cells and even in individual subcellular compartments is ever growing. FISH is the most common assay to detect target nucleic acids in individual cells with high resolution. The compatibility of ECHO-FISH with other cellular fluorescent labeling techniques allows analysis to be restricted to specific cell types and specific subcellular compartments. This method can be readily applied to a large number of biological samples with facile and cost-effective ECHO probe synthesis. We anticipate that ECHO-FISH will accelerate reliable quantitative high-throughput cytogenetic and gene-expression analysis in individual cells. Such analysis can be especially useful for cancer diagnosis, pathogen identification, epigenetic studies, comparative genomic studies, molecular anatomy, and other cell biological investigations to dissect the genetic basis of cellular behaviors.

\section{MATERIALS AND METHODS}

\section{Animal use}

To prepare primary hippocampal cultures, we purchased SpragueDawley pregnant rats (SLC, Japan) and used postnatal day 0 pups for hippocampi collection. This study was carried out in accordance with the Guide for the Care and Use of Laboratory Animals from the Society for Neuroscience and was authorized by the Animal Care and Use Committee of RIKEN.

\section{Reagents}

CaMKII $\alpha$, MAB3119 (6G9, Chemicon International, $2 \mathrm{ug} / \mathrm{mL}$ ); MAP2, (SMI52, Covance, $1 \mu \mathrm{g} / \mathrm{mL}$ ); GFAP, MAB360 (GA5, Chemicon, working concentration 1:1000); Synaptophysin, S5768 (SVP-38, Sigma, 1:500). Phalloidin-rhodamine (Molecular Probes, 1:200); ProLong mounting medium with DAPI (Molecular Probes), AraC (5 $\mu \mathrm{M}$, Sigma), Neurobasal A medium (Invitrogen), Papain (Worthington), B27 supplement (Invitrogen), Hibernate A (Brainbits LLC), Glutamax (Invitrogen), poly-L-lysine (Sigma), Horse serum (Invitrogen), BSA (Sigma), RNase A (Roche), Pepsin (Sigma), Dulbecco's modified Eagle's medium (DMEM, GIBCO), fetal bovine serum (FBS, GIBCO), penicillin (SIGMA), streptomycin (SIGMA) were purchased. Antibodies and drugs were stored in small aliquots in a $-30^{\circ} \mathrm{C}$ freezer at recommended stock concentrations.

\section{Equipment for probe synthesis and spectral measurements}

DNA was synthesized on a 392 DNA/RNA synthesizer (Applied Biosystems) or a NTS H-6 DNA/RNA synthesizer (Nihon Techno service). Reversed-phase HPLC was performed on CHEMCOBOND 5-ODS-H columns (10-150 mm) with a Gilson Chromatograph, Model 305, using a UV detector, Model 118, at $260 \mathrm{~nm}$. MALDITOF mass spectra were measured with a Bruker Daltonics Reflex.
UV and fluorescence spectra were recorded on a UV-2550 spectrophotometer and RF-5300PC spectrofluorometer (Shimadzu), respectively.

\section{Designing effective ECHO probes and probe synthesis}

Previously, we reported sequence dependency of ECHO probes and developed algorithm for effective probe design (Ikeda et al. 2008). This program predicts and avoids sequences that are prone to intra- and intermolecule dimerization, which causes compromised quenching efficiency of the TO dyes. All FISH probes in this report were designed using the same program to prevent lessefficient quenching.

Oligonucleotides were prepared by a standard phosphoramidite method on a DNA synthesizer described in our previous report (Ikeda and Okamoto 2008). The synthesized DNA oligomer containing a diamino-modified nucleotide was cleaved from the CPG support with $28 \%$ aqueous ammonia and deprotected according to the instruction of Cy5 phosphoramidite. After removal of ammonia from the solution under reduced pressure, the DNA was purified by reversed-phase HPLC elution, with a solvent mixture of $0.1 \mathrm{M}$ triethylammonium acetate (TEAA) $(\mathrm{pH} 7.0)$ and linear gradient over $20 \mathrm{~min}$, from $5 \%$ to $30 \%$ acetonitrile at a flow rate of $3.0 \mathrm{~mL} / \mathrm{min}$. A solution of the succinimidyl ester of thiazole orange dyes (50 equiv to an active amino group of DNA) in DMF was added to a solution of purified DNA in $100 \mathrm{mM}$ sodium carbonate buffer ( $\mathrm{pH} 9.0)$ and incubated at $25^{\circ} \mathrm{C}$ for $10 \mathrm{~min}$. The reaction mixture was diluted with ethanol. After centrifuging at $4^{\circ} \mathrm{C}$ for $20 \mathrm{~min}$, the supernatant was removed. The residue was dissolved in a small amount of water and then the solution was passed through a $0.45-\mu \mathrm{m}$ filter. The product was purified by reversed-phase HPLC on a 5-ODS-H column, elution with a solvent mixture of $0.1 \mathrm{M}$ TEAA ( $\mathrm{pH} 7.0$ ), and linear gradient over $28 \mathrm{~min}$ from $5 \%$ to $40 \%$ acetonitrile at a flow rate of $3.0 \mathrm{~mL} / \mathrm{min}$ ). The fluorescent DNA was identified by MALDI-TOF mass spectrometry.

\section{Absorption and fluorescence measurements}

Absorption and fluorescence spectra of the fluorescent probes were measured in DEPC/PBS or hybridization buffer (4XSSC, 0.5 mM EDTA, $10 \%$ dextran sulfate, $10 \%-25 \%$ formamide) using a cell with a $1-\mathrm{cm}$ path length. The excitation wavelength was 514 $\mathrm{nm}$ (bandwidths $1.5 \mathrm{~nm}$ ). Nucleic acids to be hybridized (singlestranded DNA, extracted RNA, etc.) were added directly into the solution containing $0.2-0.5 \mu \mathrm{M}$ probes in the cell and mixed by quick pipetting. Up to $25 \mathrm{~min}$ were allowed for hybridization before measurements were taken.

To quantify the fluorescence activation of the probes, band intensities around the emission peak (520-555 nm) were summed and used to calculate the fluorescence intensity ratio of the probes before and after hybridization.

\section{RNA extraction and purification}

Total RNA was isolated from adult rat brain using RNAqueous Kit (Ambion) and AllPrep DNA/RNA Mini kit (QIAGEN) according to the manufacture's instructions. The Oligotex- $\mathrm{dT}_{30}$ mRNA purification kit (TaKaRa) was used to purify mRNA from total rat brain RNA. 


\section{Cell cultures}

HeLa cells were maintained in DMEM containing 10\% heatinactivated $\mathrm{FBS}, 25 \mathrm{U} \mathrm{mL}^{-1}$ penicillin and $25 \mathrm{mg} \mathrm{mL}^{-1}$ streptomycin under a humidified atmosphere with $5 \% \mathrm{CO}_{2}$. Dissociated hippocampal cultures were prepared from P0 rat pups and maintained on poly-L-lysine-coated glass coverslips Briefly, hippocampi from three pups were pooled for digestion in papain/hibernate A $\left(40 \mathrm{U} / \mathrm{mL}\right.$ ) solution at $37^{\circ} \mathrm{C}$ for $20 \mathrm{~min}$. At the end of digestion, the hippocampi were triturated in plating medium (neurobasal medium containing 10\% horse serum, 2\% B27 supplement, glutamate, and $20 \mathrm{mM}$ HEPES) by gentle pipetting. Cells were pelleted (450 g, $5 \mathrm{~min}$ ) and resuspended in plating medium. After cell density counting, 60,000 cells were plated in each well of 24 -well plates $(\sim 1$ $\mathrm{mL}$ ). After $2-3 \mathrm{~h}$, plating medium can be replaced by growth medium (neurobasal medium supplemented with B27 supplement and glutamate). AraC ( $5 \mu \mathrm{M}$, final concentration) was added to the cultures at $3 \mathrm{~d}$ in vitro (DIV3 with the day of preparation as DIV0). After DIV3, cultures were fed every $4 \mathrm{~d}$ by exchanging half of the volume $(0.5 \mathrm{~mL})$ of culture medium with fresh growth medium and kept in a $37^{\circ} \mathrm{C}$ incubator injected with $5 \% \mathrm{CO}_{2}$.

\section{RNA-FISH}

HeLa cells and dissociated hippocampal cultures were fixed in $4 \%$ paraformaldehyde at room temperature for $15 \mathrm{~min}$. After rinsing with DEPC-PBS, cells were permeabilized in TritonX-100/DEPC/ PBS $(0.5 \%$ for HeLa cells and $0.1 \%$ for primary hippocampal cultures) for $5 \mathrm{~min}$. After rinsing with PBS, ECHO probes were diluted and applied at $200 \mathrm{nM}$ in hybridization buffer (4XSSC, 0.5 mM EDTA, 10\% dextran sulfate, 10\%-25\% deionized-formamide in DEPC $-\mathrm{H}_{2} \mathrm{O}$ ) and incubated at room temperature for $1 \mathrm{~min}$ to overnight. The hybridized samples were mounted onto glass slides with ProLong self-solidifying mounting medium.

Including $10 \%-25 \%$ formamide in the hybridization buffer effectively "linearized" most probes, so that D514 probes emit little fluorescence in the absence of target RNA. When we tested the effective position of D514 within the sequence, it seems that the ON/OFF mechanism is consistently effective when D514 is away from the ends of the probes by at least $3 \mathrm{nt}$ (data not shown).

We used conventional FISH protocols to detect poly(A) localization pattern with Cy5-d(T) $)_{30}$ and/or $\mathrm{T}_{6} \mathrm{D} 514 \mathrm{~T}_{6}$ : HeLa cells were fixed in $4 \%$ paraformaldehyde at room temperature for 15 min, rinsed with PBS and 2XSSC; $0.2 \mu \mathrm{M}$ probes were applied in 4XSSC, $0.5 \mathrm{mM}$ EDTA, $10 \%$ dextran sulfate, $10 \%$ deionizedformamide in DEPC $-\mathrm{H}_{2} \mathrm{O}$. Hybridization was done at $37^{\circ} \mathrm{C}$ for $3 \mathrm{~h}$ to overnight. After hybridization, cells were washed in 2XSSC, 3X $15 \mathrm{~min}$ and PBS, 3X $15 \mathrm{~min}$ at room temperature.

\section{DNA-FISH}

Mitotic mouse ES cells (SCRC-1010, purchased from ATCC) were maintained in CultiCell medium for ES cells (Stem Cell Science KK) supplemented with $0.1 \mathrm{mM}$ 2-mercaptolethanol and 1,000 U/ $\mathrm{mL}$ LIF. To prepare metaphase chromosome spreads, cells were collected after growing in medium containing $0.1 \mu \mathrm{g} / \mathrm{mL}$ of KaryoMAX Colcemid solution (Invitrogen) for $6 \mathrm{~h}$. After hypotonic treatment in $75 \mathrm{mM} \mathrm{KCl}$, cells were fixed in methanol/acetic acid (3:1, freshly prepared) by gentle resuspension. The fixed samples were stored at $-30^{\circ} \mathrm{C}$ until use.
To perform DNA-FISH, metaphase chromosome spreads were spotted onto gelatin-coated glass slides and let dry. After RNase treatment $\left(200 \mu \mathrm{g} / \mathrm{mL}, 1 \mathrm{~h}\right.$ at $\left.37^{\circ} \mathrm{C}\right)$ and pepsin treatment $(2 \%$ pepsin in $0.01 \mathrm{~N} \mathrm{HCl}, 1 \mathrm{~h}$ at room temperature), cells were washed in $\mathrm{PBS}$ and dehydrated through an $\mathrm{EtOH}$ gradient $(70 \%, 90 \%$, and $100 \%$ for $10 \mathrm{~min}$ each). Samples were heated at $80^{\circ} \mathrm{C}$ for $3 \mathrm{~min}$ to separate DNA strands, then $1.25-12.5 \mathrm{ng} / \mathrm{uL}$ of probes in hybridization buffer (4XSSC, $0.5 \mathrm{mM}$ EDTA, 10\% dextran sulfate, $25 \%$ deionized-formamide in DEPC- $\mathrm{H}_{2} \mathrm{O}$ ) were applied and incubated at room temperature for $2 \mathrm{~h}$ before imaging.

\section{Epifluorescence and confocal imaging and analysis}

Epifluorescence imaging was used for screening probes and optimizing FISH protocols. Specific filter sets were used to separate fluorescence signals: ECHO probes D514 (ex 500/2425, dm 520, em 542/25-27), DAPI, (G 365, FT 395, BP 445/50), mStrawberry and Alexa 546 (ex BP 545/25, dm FT 570, em 605/ 70), D715 (ex 685AF30, dm 708DRLP, em730AF30).

Confocal microscopy was used to analyze cellular and subcellular concentrations of target RNA such as poly(A) RNA (LSM510 and 780, Zeiss), D488 (Argon 488, MBS 488, em 489$560 \mathrm{nnm}$ ), D514 (Argon 514, MBS 458/514, em 510-577 nm), D570 (DPSS561-10, MBS 488/561, em 589-650 nm), D600 (DPSS561-10, MBS 488/561, em 602-670 nm), D640 (HeNet 633, MBS 488/561/633, em 640-670 nm), Cy5 (HeNet 633, em 640$760)$. Optical slices were collapsed into single images before export to TIFF images for analysis.

Automated image analysis was done with CellProfiller (MIT). Pipelines were generated to direct object-oriented analysis and sample images were monitored to optimize analysis parameters.

\section{Statistical analysis}

Prism GraphPad software was used for all statistical analysis; ANOVA analysis followed by Bonferroni's multiple comparisons, ANOVA analysis followed by Dunnett's multiple comparisons, and $t$-test were performed.

\section{SUPPLEMENTAL MATERIAL}

Supplemental material is available for this article.

\section{ACKNOWLEDGMENTS}

We thank lab members of the A. Okamoto lab and Y. Hayashi lab for helpful discussions and Dr. Shinichi Nakagawa for critical reading of the manuscript. This work is funded by a Grant-in-Aid for JSPS fellows (\#22-00212) from the Japan Society for the Promotion of Science to A.O. and D.O.W., Grant-in-Aid Startup to D.O.W., RIKEN, NIH grant R01DA17310, Grant-in-Aid for Scientific Research (A), and Grant-in-Aid for Scientific Research on innovative area "Foundation of Synapses and Neurocircuit Pathology" from MEXT to Y.H.

Received July 8, 2011; accepted October 3, 2011.

\section{REFERENCES}

Bauman JG, Wiegant J, Borst P, van Duijn P. 1980. A new method for fluorescence microscopical localization of specific DNA sequences 
by in situ hybridization of fluorochromelabelled RNA. Exp Cell Res 128: 485-490.

Benson DL, Gall CM, Isackson PJ. 1992. Dendritic localization of type II calcium calmodulin-dependent protein kinase mRNA in normal and reinnervated rat hippocampus. Neuroscience 46: 851-857.

Burgin KE, Waxham MN, Rickling S, Westgate SA, Mobley WC, Kelly PT. 1990. In situ hybridization histochemistry of $\mathrm{Ca}^{2+} / \mathrm{calmodulin}^{-}$ dependent protein kinase in developing rat brain. J Neurosci 10: $1788-1798$.

Femino AM, Fay FS, Fogarty K, Singer RH. 1998. Visualization of single RNA transcripts in situ. Science 280: 585-590.

Gong S, Zheng C, Doughty ML, Losos K, Didkovsky N, Schambra UB, Nowak NJ, Joyner A, Leblanc G, Hatten ME, et al. 2003. A gene expression atlas of the central nervous system based on bacterial artificial chromosomes. Nature 425: 917-925.

Guenatri M, Bailly D, Maison C, Almouni G. 2004. Mouse centric and pericentric satellite repeats form distinct functional heterochromatin. J Cell Biol 166: 493-505.

Horbinski C, Miller CR, Perry A. 2011. Gone FISHing: clinical lessons learned in brain tumor molecular diagnostics over the last decade. Brain Pathol 21: 57-73.

Ikeda S, Okamoto A. 2008. Hybridization-sensitive on-off DNA probe: application of the exciton coupling effect to effective fluorescence quenching. Chem Asian J 3: 958-968.

Ikeda S, Kubota T, Kino K, Okamoto A. 2008. Sequence dependence of fluorescence emission and quenching of doubly thiazole orange labeled DNA: effective design of a hybridization-sensitive probe. Bioconjug Chem 19: 1719-1725.

Ikeda S, Kubota T, Yuki M, Okamoto A. 2009. Exciton-controlled hybridization-sensitive fluorescent probes: multicolor detection of nucleic acids. Angew Chem Int Ed Engl 48: 6480-6484.

Ikeda S, Yanagisawa H, Nakamura A, Wang DO, Yuki M, Okamoto A. 2011. Hybridization-sensitive fluorescence control in the nearinfrared wavelength range. Org Biomol Chem 9: 4199-4204.

Klonisch T, Wark L, Hombach-Klonisch S, Mai S. 2010. Nuclear imaging in three dimensions: a unique tool in cancer research. Ann Anat 192: 292-301.

Krug MS, Berger SL. 1986. A micromethod for measuring the molar concentration of polyadenylated RNA in the presence of ribosomal RNA. Anal Biochem 153: 315-323.

Langer PR, Waldrop AA, Ward DC. 1981. Enzymatic synthesis of biotin-labeled polynucleotides: novel nucleic acid affinity probes. Proc Natl Acad Sci 78: 6633-6637.

Larsson C, Grundberg I, Söderberg O, Nilsson M. 2010. In situ detection and genotyping of individual mRNA molecules. Nat Methods 7: 395-397.

Lee LG, Chen CH, Chiu LA. 1986. Thiazole orange: a new dye for reticulocyte analysis. Cytometry 7: 508-517.

Lein ES, Hawrylycz MJ, Ao N, Ayres M, Bensinger A, Bernard A, Boe AF, Boguski MS, Brockway KS, Byrnes EJ, et al. 2007. Genome-wide atlas of gene expression in the adult mouse brain. Nature 445: 168-176.

Levsky JM, Shenoy SM, Pezo RC, Singer RH. 2002. Single-cell gene expression profiling. Science 297: 836-840.

Lichter P, Cremer T, Borden J, Manuelidis L, Ward DC. 1988. Delineation of individual human chromosomes in metaphase and interphase cells by in situ suppression hybridization using recombinant DNA libraries. Hum Genet 80: 224-234.
Manuelidis L, Langer-Safer PR, Ward DC. 1982. High-resolution mapping of satellite DNA using biotin-labeled DNA probes. J Cell Biol 95: 619-625.

Netzel TL, Nafisi K, Zhao M, Lenhard JR, Johnson I. 1995. Basecontent dependence of emission enhancements, quantum yields, and lifetimes for cyanine dyes bound to double-strand DNA: Photophysical properties of monomeric and bichromophoric DNA stains. J Phys Chem 99: 17936-17947.

Nielsen PE, Egholm M, Berg RH, Buchardt O. 1991. Sequenceselective recognition of DNA by strand displacement with a thymine-substituted polyamide. Science 254: 1497-1500.

Nilsson M, Malmgren H, Samiotaki M, Kwiatkowski M, Chowdhary BP, Landegren U. 1994. Padlock probes: circularizing oligonucleotides for localized DNA detection. Science 265: 2085-2088.

Nygren J, Svanvik N, Kubista M. 1998. The interactions between the fluorescent dye thiazole orange and DNA. Biopolymers 46: 39-51.

Raj A, van den Bogaard P, Rifkin SA, van Oudenaarden A, Tyagi S. 2008. Imaging individual mRNA molecules using multiple singly labeled probes. Nat Methods 5: 877-879.

Rudkin GT, Stollar BD. 1977. High resolution detection of DNA-RNA hybrids in situ by indirect immunofluorescence. Nature 265: 472473.

Rye HS, Yue S, Wemmer DE, Quesada MA, Haugland RP, Mathies RA, Glazer AN. 1992. Stable fluorescent complexes of doublestranded DNA with bis-intercalating asymmetric cyanine dyes: properties and applications. Nucleic Acids Res 20: 2803-2812.

Schins JM, Agronskaia A, de Grooth BG, Greve J. 1999. Orientation of the chromophore dipoles in the TOTO-DNA system. Cytometry 37: 230-237.

Schrock E, du Manoir S, Veldman T, Schoell B, Wienberg J, FergusonSmith MA, Ning Y, Ledbetter DH, Bar-Am I, Soenksen D, et al. 1996. Multicolor spectral karyotyping of human chromosomes. Science 273: 494-497.

Sharpe J, Ahlgren U, Perry P, Hill B, Ross A, Hecksher-Sørensen J, Baldock R, Davidson D. 2002. Optical projection tomography as a tool for 3D microscopy and gene expression studies. Science 296: $541-545$.

Sieben VJ, Debes-Marun CS, Pilarski LM, Backhouse CJ. 2008. An integrated microfluidic chip for chromosome enumeration using fluorescence in situ hybridization. Lab Chip 8: 2151-2156.

Silahtaroglu A, Pfundheller H, Koshkin A, Tommerup N, Kauppinen S. 2004. LNA-modified oligonucleotides are highly efficient as FISH probes. Cytogenet Genome Res 107: 32-37.

Singer RH, Ward DC. 1982. Actin gene expression visualized in chicken muscle tissue culture by using in situ hybridization with a biotinated nucleotide analog. Proc Natl Acad Sci 79: 7331-7335.

Speicher MR, Gwyn Ballard S, Ward DC. 1996. Karyotyping human chromosomes by combinatorial multi-fluor FISH. Nat Genet 12: 368-375.

Trask BJ. 2002. Human cytogenetics: 46 chromosomes, 46 years and counting. Nat Rev Genet 3: 769-778.

van de Corput MPC, Dirks RW, van Gijlswijk RPM, van Binnendijk E, Hattinger CM, de Paus RA, Landegent JE, Raap AK. 1998. Sensitive mRNA detection by fluorescence in situ hybridization using horseradish peroxidase-labeled oligodeoxynucleotides and tyramide signal amplification. J Histochem Cytochem 46: 12491259. 

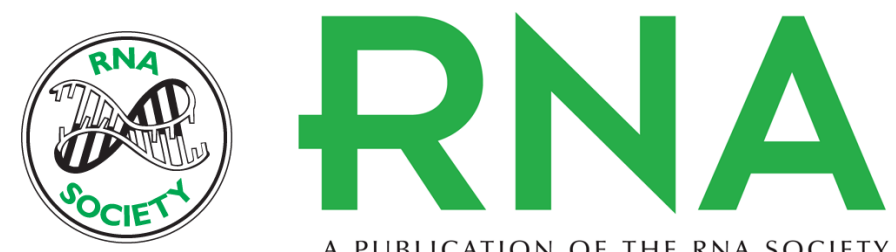

A PUBLICATION OF THE RNA SOCIETY

\section{A quick and simple FISH protocol with hybridization-sensitive fluorescent linear oligodeoxynucleotide probes}

Dan Ohtan Wang, Hitomi Matsuno, Shuji Ikeda, et al.

RNA 2012 18: 166-175 originally published online November 18, 2011

Access the most recent version at doi:10.1261/rna.028431.111

\section{Supplemental http://rnajournal.cshlp.org/content/suppl/2011/11/03/rna.028431.111.DC1 \\ Material}

References This article cites 36 articles, 11 of which can be accessed free at:

http://rnajournal.cshlp.org/content/18/1/166.full.html\#ref-list-1

\section{License}

Email Alerting Receive free email alerts when new articles cite this article - sign up in the box at the Service top right corner of the article or click here.

\section{|||||||| Providing Precise Solutions for your research.}

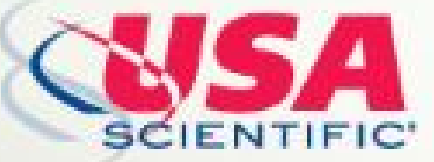

To subscribe to $R N A$ go to:

http://rnajournal.cshlp.org/subscriptions 